\title{
LETTERS
}

\section{Short-term increase in self- reported cannabis use to be expected}

If cannabis use goes up in the short term [after legalization], we need to be leery of reporting bias. We should expect consumers to be more forthcoming in surveys, and less fearful of reporting and seeking help for adverse events and accidental ingestion, improvements in transparency that the CMAJ should welcome.

Controlling for reporting bias, usage rates may still go up in the short term before social customs and mores have a chance to evolve and cannabis becomes "normalized." Criminal prohibition drove a wedge between physicians and patients, parents and children, teachers and students, and the police and their communities. Historically, there has been no statistical relationship between usage rates, cannabis laws, enforcement levels and criminal penalties. One wonders what amendments to the Cannabis Act Dr. Kelsall ${ }^{1}$ has in mind [if cannabis use should increase] and on what criminological evidence the government would base those amendments.

\section{Matthew M. Elrod}

Librarian, Canadian Media Awareness

Project, Metchosin, BC

Cite as: CMAJ 2019 January 28;191:E108. doi: $10.1503 / \mathrm{cmaj} .71135$

\section{Reference}

1. Kelsall D. Watching Canada's experiment with legal cannabis. CMAJ 2018;190:E1218.

This is an abridged version of a response posted online at cmaj.ca.

Competing interests: None declared. 